\title{
Matthew Porteous, Susanne Bäuerle: Techniques and principles for the operating room: AO-trauma
}

\author{
Thieme Verlag, New York, Stuttgart, 2010, 730 pp, 1200 figs., Hardcover, EUR \\ (D) 109,95 CHF 183,00, ISBN: 978-3-13-151081-5, e-ISBN 978-3-13-151091-4
}

Pierre Kehr

Received: 24 November 2011 / Accepted: 26 November 2011/Published online: 7 December 2011

(c) Springer-Verlag 2011

What is special about this book is that it is intended for trauma surgeons of course, and also, and that is new, for all staff working in the operating room in a broad sense. The purpose of this guide is to provide a description of the traumas of the limbs and pelvis, designed to be as simple and accessible as possible.

The first two sections deal with an overview of the equipment for trauma management and then the general principles of the treatment for fractures.

The last part provides guidance on the action to be taken in common fractures.

Each chapter is structured similarly, from patient's arrival to operative care, from postoperative days to followup, step by step.
Moreover, key points for the surgeon and for the nurses are listed.

Classifications are, of course, those of the AO as well as the surgical instrumentation presented.

This book will thus interest junior surgeons as well as the nursing staff of the operating room.

Alain Graftiaux

Strasbourg

Conflict of interest No funds were received in support of this study.

This book review was previously published in ArgoSpine News and Journal (2011) 23:174. doi:10.1007/s12240-011-0032-8.

P. Kehr $(\bowtie)$

Strasbourg, France

e-mail: kehrpier@aol.com 